\title{
Deep Development of Yuping Flute Products and Development of Xiao Flute Culture
}

\author{
Ren Yuanchun \\ Music Exhibition Department, School of Art, Tongren College, Guizhou Province, 554300
}

Keywords: Yuping flute; deep development; Xiao flute culture; development

\begin{abstract}
Our country is a cultural country with a history of 5000 years. Xiao flute has a long history in our country. While Yuping Xiao flute is famous for its excellent quality, unique shape, exquisite craft, and rhyme of Qing Dynasty, and has won many awards in the world. Since the creation, the Yuping Xiao flute has experienced more than 600 years of development history. In 2006, the State Council has listed it as the object of non-material cultural protection with its excellent quality. As an important part of Chinese traditional culture, the Xiao flute in Yuping has an important role in the further dissemination of the culture of the sishaw flute, so it should strengthen its protection. This paper, taking the deep development of Xiao flute product in Yuping and the development of Xiao flute culture as the breakthrough point, expounds the necessity of speeding up the deep development of the shaute flute in Yuping, analyzes the difficulties of the deep development of the shaute flute in Yuping, and puts forward some countermeasures to speed up the inheritance and development of the Shaxiao flute in Yuping on this basis, and hopes to promote the deep development of the Xiao flute products in Yuping and Xiao Diwen, which has a certain positive impact on further development.
\end{abstract}

\section{Introduction}

In our country, the "three treasures of Guizhou" is well-known. Its three treasures include Guizhou Moutai, Yuping Xiao flute and lacquer ware. The Yuping people carved all kinds of lifelike shapes on Yuping's flute with superb skills. Their exquisite workmanship and exquisite sculpt are amazing. In recent years, with the gradual increase of national protection of intangible cultural heritage, Yuping Xiao flute has also entered a new period of development. Yuping people are committed to creating the cultural brand of Yuping's Xiao flute, striving to the greatest extent, to make the Shaxiao flute in Yuping to the world and to spread the culture of the Shaxiao flute in Yuping. In the sixth Plenary Session of the 17th CPC Central Committee, the decision on deepening the reform of the cultural system to promote the great development and prosperity of the socialist culture, which was adopted by the party in the sixth Plenary Session of the 17th CPC Central Committee, provides a solid system guarantee for the long-term development of the Xiao flute in Yuping. Therefore, the development of Xiao flute production in Yuping and the cultural development of Xiao flute are carried out at the present time. The discussion is of great practical significance. Two, the necessity of speeding up the deep development of the Shaxiao flute in Yuping[1]

\section{The Requirement of the Cultural Development of Xiao Flute}

In recent years, the development of Xiao Di culture has shown a good momentum. This cultural situation has put forward new requirements for the deep development of Yuping Xiao di. The deep development of Xiao flute in Yuping has an important influence on the development and dissemination of the culture of Xiao flute. Therefore, it is an inevitable requirement for the development of Xiao flute to accelerate the development of Xiao flute in Yuping. Yuping Xiao flute was born in the Yongle period of the Ming Dynasty more than 600 years ago. Unlike a Sixiao flute in the early stage of development, the main business model is different. Today's Yuping Xiao flute has already owned more than 100 varieties of seven Shaw twelve flute, and its superior quality and 
perfect equipment have brought up the annual sales volume of Yuping Xiao flute by more than 260000 The outstanding achievement of the branch. Today, Yuping Xiao flute has become one of the four largest national musical instrument manufacturers in China. After the founding of new China, the development of the culture of Xiao flute has been highly concerned. In particular, with the concern of the party and the government, great progress has been made in the spread of the culture of the sishaw in Yuping. In recent years, with the success of the Shaxiao flute art festival in Yuping and the successful hosting of the national Xiao flute playing tournament in Yuping, the development of the Shaxiao flute in Yuping and the deep spread of the culture of the Shaxiao flute in Yuping have been greatly promoted. With the continuous development of China's social economy and the improvement of the people's living standards, the quality and conservation of spiritual and cultural products are increasing. Therefore, the existing Yuping Xiao flute must be improved to a certain extent, and the quality of its quality should be deeply developed to ensure that its quality meets the needs of modern people's spiritual and cultural needs. . Only on this basis can we ensure that the development of Yuping Xiao Di can be stable and long-term[2].

At present, with the prosperity and development of the social economy, the flute products in our country have diversified development trend, and the number of the Sixiao flute manufacturers is increasing gradually. Therefore, the competition of the sishadi market is becoming increasingly fierce. The carving craft of Yuping's Xiao Didi, with its elegance and adept features, has been favored by a lot of enthusiasts and is well known for its silver medal in the international handicraft exhibition in London, England in 1913. In essence, Yuping Xiao flute is a kind of playing instrument, but a considerable number of people think that Yuping Sixiao flute is more of the arts and crafts, which is a great misunderstanding of the value function of the shaute flute in Yuping. Therefore, in order to maintain the survival and development of the Shaxiao flute in the fierce market competition of the shaute flute, it is necessary for the Yuping Xiao flute to be kept in the fierce competition of the shaute flute product market. Further development should be carried out to promote its continuous development and innovation so as to meet the requirements of fierce market competition.

\section{Difficulties and Corresponding Solutions for Deep Development of Yuping Shaw Flute}

Yuping Xiao flute has a long history, high product quality and large scale of production, and has won the favor of Xiao flute enthusiasts for its superior quality. In particular, with the attention of the party and the government, the Yuping Xiao flute has achieved a leap forward development. In the past fifty years, Yuping's Xiao flute has realized a great change from a whistle to a seven Shaxiao twelve flute, but it is undeniable that the production grid of the shaolute in Yuping has become increasingly narrow in the year of twentieth Century and the development of the product has gradually become more and more gradual. Slowly, the market competitiveness has gradually declined. The reason is that the Shaxiao flute in Yuping lacks the consciousness of innovation, and is overly dependent on the traditional mode of the development of the Shaxiao flute, and is relatively inadequate in the development of new technology and new products. The survey shows that the number of manufacturers in Yuping's Shaxiao flute has gradually increased in recent years, the quality of its products is not effectively guaranteed and the innovation is insufficient. The problems such as the lack of beauty of sound, the outmoded style of the Shaxiao and the uneven quality often appear, which greatly hinders the deep development of the Shaxiao flute in Yuping and makes the Yuping Siao flute in the market The percentage of the occupancy is decreasing[3].

To achieve remarkable results in product innovation, adequate capital investment is one of the prerequisites. However, the problem that can not be ignored is that, at the present stage, due to the decline of the competitiveness of the sishadi market in Yuping and the reduction of economic benefits, the enterprise development funds are relatively tight, and it is difficult to guarantee the effective investment in the innovative funds. This has a critical impact on the innovative development of the shaute flute in Yuping. In addition, the low willingness of banks to invest in Yuping Xiao flute is also one of the important factors that lead to the lack of investment in the innovation funds of Yuping sishadi. Since the innovative investment of the Yuping Siao flute has a 
large risk and its innovation cycle is relatively long, it is difficult to get the favor of the bank investment. Yuping county is relatively poor county, and government funds are relatively scarce. Therefore, it is hoped that Yuping county government will invest less in Yuping's Innovation Fund. In view of all the factors above, the shortage of innovative funds in Yuping's Shaxiao flute has become an important factor hindering the deep development of Yuping's Shaxiao flute. Therefore, effective measures must be taken to secure sufficient development funds for the innovative development of Yuping's Xiao flute and the deep development of the product.

\section{Lack of Talent is Serious}

The quality and quantity of talents are of great importance for product innovation and product depth development. Now the responsible and a considerable number of skilled workers in the Yuping Xiao flute factory are trained in 1950s, but since 90s, the young apprentices who have been recruited after 90s are inadequate, and their ability to endure hardships and hardships is relatively low, and the gap between the old workers and the old workers is very large. It has caused the new apprentices to support the deep development of Shaw flute in Yuping after the retirement of the veteran workers, which makes the shortage of talents in Yuping Xiao Di factory extremely serious. The relevant investigation shows that at present, only less than ten workers in the shaute factory of Yuping have come to work to maintain the product management of Yuping's Xiao flute enterprises. The cause of this situation is in the final analysis, in the final analysis of the temptation of economic interests. More and more people have chosen the way of self seeking, which greatly adds to the serious situation of the shortage of talent in Yuping's Xiao flute. Noodles[4].

\section{Measures to Speed up the Development of the Shaxiao Flute in Yuping}

Culture occupies an important position in the economic development. The existence of certain cultural factors can make the economic development full of vitality and get rid of the boring development model. Only by creating a strong cultural atmosphere in the wider range can more people fall in love with Xiao Di culture, thus forming a great impetus for the production and sale of Yuping's Xiao flute. enhance the understanding of the importance and necessity of developing Xiao Di culture. Yuping Xiao flute has a long history and culture, and the product is rich in connotation. When people mention that Xiao flute often thinks of Yuping, it is a very valuable resource to carry forward and spread it further, so that the cultural benefit of the Shaxiao flute in Yuping will promote the deep development of the Shaxiao flute in Yuping. Second, efforts should be made to build a suitable environment for the development of Xiao Di culture. The overall development trend of Xiao flute culture will have a great impact on the development of the sishaw flute in Yuping. Therefore, we should set up a view of the overall development and long-term development of the culture of Xiao flute, and try to build a good cultural atmosphere of enterprise operation, social participation and government support. Specifically, the construction of a good Yuping Xiao flute development conditions can start from the following two aspects. First of all, it is clear that the Yuping Xiao flute represents the Dong culture to a great extent. It should take the Dong culture as the focus to create a national cultural ecological garden, to the greatest extent, to make the Yuping Xiao flute with the cultural connotation of the Dong nationality, and to promote the deep development of the Shaxiao flute in Yuping with the highlight of the cultural connotation of the national culture. Secondly, a large-scale Shaw culture and Art Festival will be held in Yuping. In order to realize the deep development of the sishadi in Yuping, it is necessary to make Yuping Xiao flute well known in a wider range. With the opportunity to carry forward the culture of Xiao flute, it can promote the prestige of the Sixiao flute in Yuping, promote the investment for investment, and realize the long-term development of the Shaxiao flute in Yuping[5].

In order to realize the long-term development of products, ensuring the quality and quantity of talents is a crucial factor. It is clear that the deep development of Yuping Xiao flute must be based on the promotion of the quality of talents and the guarantee of the number of talents. Only on this basis can the development of Yuping Sixiao flute have a solid foundation of talent. In order to 
ensure the quality and quantity of Yuping Shaw talents, we must pay attention to the following three aspects. First of all, attach importance to the cultivation of Xiao Diyao's talent. It is of great significance for Xiao flute to carry forward the culture of Xiao flute. In order to realize the purpose of cultivating the talent of Xiao flute, we can consider the cultural teaching activities of Xiao flute into the campus in the primary and secondary schools in the county, and set up the playing lesson of Xiao flute in primary and secondary schools, and improve the understanding and love of Xiao flute playing. At the same time, the sishaw playing competition can be held in Yuping county to attract more people to learn Xiao flute and play the Sixiao flute, so that Xiao flute can play a good atmosphere in the whole society. Secondly, we should make clear the truth of winning the victory by quality. It should be realized that the development of the Sixiao flute in Yuping ultimately depends on its quality. Therefore, it is necessary to attach importance to the training of the production personnel of the sishaw flute, and to make strict requirements on the production process and respect to ensure that the quality of the shaute flute in Yuping is in accordance with the requirements of his post. Finally, we pay enough attention to the cultivation of Yuping Xiao Di business management talents. The ability and quality of enterprise managers will largely affect the quality and level of development of enterprises. Therefore, in order to ensure the long-term development of the health of Yuping Xiao flute enterprise, it is necessary to carry out deep training to its enterprise managers and establish a high quality management talent team to ensure the healthy and long-term development of the Shaxiao flute in Yuping[6].

General secretary Jiang Zemin once pointed out that "innovation is the soul of a nation's progress and an inexhaustible motive force for the prosperity of a country." President xi jinping further pointed out that "innovation and innovation should be encouraged to promote the development of cultural innovation with exquisite art."Similarly, for the development of enterprises, in order to ensure the long-term healthy development of the enterprises, we must keep their own energy to create new ideas and develop new products to meet the increasingly diverse needs of cultural products in modern society. It is also necessary to make clear that the Yuping Xiao flute must be based on the more than 600 years of historical development, in-depth analysis of the new requirements of the modern society for the Xiao flute, the development in the reform, and innovation to preserve the survival. To achieve the innovation and development of Yuping Xiao Di, we need to start from the following two aspects. (1) introduce modern technology in the deep development of Yuping Xiao Di products. At present, there is a serious problem in the production of Yuping Xiao flute. Therefore, we must base on the traditional handicrafts of Yuping Xiao Di, and introduce modern scientific and technological means to optimize some production processes in the process of production. Second, promote the diversified development of Yuping Xiao flute production process. The diversification of the production technology of the sishaw flute in Yuping is the basis for the realization of the diversification of the shaute flute and the source of Xiao flute's product innovation, so it must be paid enough attention to it. At present, the production process of our country's Xiao flute is relatively simple, and the main aspects of the product carving are dragon phoenix pattern and poetry and words and sentences, and the similarity of pattern and font type is high, which makes the overall level of Xiao flute difficult to be effectively improved, which is not conducive to the increase of the sales of Xiao flute. Therefore, we must pursue the diversification of the carving, packaging and production of Xiao flute, and strive to promote the innovation and development of Yuping's Xiao flute to the greatest extent, and realize the deep development of the Shaxiao flute in Yuping.

\section{Conclusion}

In the background of promoting the great development and prosperity of the socialist culture in our country, the people of Yuping are committed to the deep development of the Shaxiao flute in Yuping and the extensive spread of Yuping culture. This is highly consistent with the idea of the cultural development of the party and the government and has an important role in promoting the building of a cultural and spiritual power. For the development dilemma of the contemporary Yuping Xiao flute, we should pay enough attention to it, make it based on the tradition, open up and 
innovate, and bear the important task of carrying forward the culture of Xiao flute. This article, taking the deep development of Xiao flute products in Yuping and the development of Xiao flute culture as the breakthrough point, discusses the necessity of speeding up the deep development of the shaute flute in Yuping, for example, speeding up the deep development of the Shaxiao flute in Yuping is the requirement of the cultural development of Xiao flute and the fierce market competition. The difficulties in the deep development of the Shaxiao flute in Yuping are analyzed, for example, lack of awareness of innovation, lack of funds and serious shortage of talents. On this basis, some measures are put forward, such as creating the cultural atmosphere of the Sixiao flute, creating conditions for the deep development of the shaute flute in Yuping, strengthening the training of talents and increasing the consciousness of innovation. Shi hopes to promote the development of Yuping flute products and the further development of Xiao flute culture.

\section{References}

[1] Prairie M, Lei D. Analysis of the tonehole lattice of the northern xiao flute[J]. Acoustical Society of America Journal, 2017, 141(5):3961-3961.

[2] Folklore E \&. The Cultural Significance of the Pueblo Indian Flute[J]. 2017.

[3] Song Y L, Zhang J J, University F N. Aesthetic Analysis of Bamboo Flute Creation and Performance after the Founding of PRC[J]. Journal of Fuyang Normal University, 2016.

[4] Song Z. On Development and Change of Cucurbit Flute Music of the Dai Ethnic Group in Yunnan[C]// International Conference on Education, Sports, Arts and Management Engineering. 2016.

[5] Yang W. A Survey on Development of Bamboo Flute Music in Hong Kong in the 20 (th) Century[J]. Explorations in Music, 2016.

[6] Yang Z, Yang F, Zhang D, et al. Phosphorylation of G protein-coupled receptors: from the barcode hypothesis to the flute model[J]. Molecular Pharmacology, 2017: mol.116.107839. 